\title{
Expression of Muscle-type Phosphorylase in Innervated and Aneural Cultured Muscle of Patients with Myophosphorylase Deficiency
}

\author{
Andrea Martinuzzi, Lodovica Vergani, Rosalba Carrozzo, Marina Fanin, Lucia Bartoloni, \\ Corrado Angelini, Valerie Askanas, * and W. King Engel* \\ Neuromuscular Center, University of Padova, 35128 Italy; and *Neuromuscular Center, University of Southern California \\ School of Medicine, Los Angeles, California 90017
}

\begin{abstract}
Patients with McArdle's myopathy lack muscle glycogen phosphorylase (M-GP) activity. Regenerating and cultured muscle of patients with McArdle's myopathy presents a glycogen phosphorylase (GP) activity, but it is not firmly established whether M-GP or non-M-GP isoforms are expressed.

We have cultured myoblasts from biopsy specimen of five patients with McArdle's myopathy. Skeletal muscle was cultured aneurally or was innervated by coculture with fetal rat spinal cord explants. In the patients' muscle biopsies and in their cultured innervated and aneural muscle we studied total GP activity, isoenzymatic pattern, reactivity with anti-M-GP antiserum, and presence of M-GP $\mathrm{mRNA}$. There was no detectable enzymatic activity, no immunoreactivity with anti-M-GP antiserum, and no M-GP mRNA in the muscle biopsy of all patients. GP activity, M-GP isozyme, and anti-M-GP antiserum reactivity were present in patients' aneural cultures, increased after innervation, and were undistinguishable from control. M-GP mRNA was demonstrated in both aneural and innervated cultures of patients and control by primer extension and PCR amplification of total RNA. Our studies indicate that the M-GP gene is normally transcribed and translated in cultured muscle of patients with myophosphorylase deficiency. ( $J$. Clin. Invest. 1993. 92:1774-1780.) Key words: glycogenosis type $\mathrm{V} \cdot$ human muscle glycogen phosphorylase $\bullet$ muscle culture
\end{abstract}

\section{Introduction}

Myophosphorylase deficiency (McArdle's myopathy, glycogenosis type V) is characterized by failure of muscle glycogen breakdown into lactic acid (1) and is due to lack of muscle glycogen phosphorylase (M-GP) ${ }^{1}$ activity $(2,3)$. Molecular studies of myophosphorylase deficiency revealed that in most

A preliminary report of this work has been presented (1990. Neurology. 40 [Suppl.]:413.

Address reprint requests to Andrea Martinuzzi M.D., Ph.D., Department of Neurology, University of Padova, via Giustiniani 5, 35128 Padova, Italy.

Received for publication 6 January 1992 and in revised form 26 April 1993.

1. Abbreviations used in this paper: B-GP, brain-type phosphorylase; GP, glycogen phosphorylase; IEF, iso-electric focusing; L-GP, livertype phosphorylase; M-GP, muscle glycogen phosphorylase; TTBS, Tween-20.

J. Clin. Invest.

(C) The American Society for Clinical Investigation, Inc.

0021-9738/93/10/1774/07 \$2.00

Volume 92, October 1993, 1774-1780 cases the protein is absent and the mRNA is missing or greatly reduced (4-6), in some patients there is a normal amount of either full-length or shorter mRNA, and in a few patients an inactive protein of normal or reduced size can be shown by immunoreaction with anti-M-GP antiserum (5-9). In human tissues there are three different isoforms of glycogen phosphorylase (GP) (10), which are encoded by three separate genes (11-13). M-GP is expressed mainly in adult skeletal muscle, liver-type phosphorylase (L-GP) is present in liver, brain-type phosphorylase (B-GP) is found mainly in the nervous tissue, L-GP and B-GP are also expressed in most adult tissues other than muscle, and in fetal tissues including skeletal muscle. During muscle maturation, L-GP and B-GP isozymes are gradually replaced by M-GP, which is barely detectable in myotubes but is the only isoform in adult muscle fibers $(14,15)$.

The gradual shift of isoenzymatic pattern during myogenesis can be observed also in cultured human muscle that has been innervated by fetal rat spinal cord neurons (16). Differentiation of human skeletal muscle in culture is greatly enhanced by innervation (17), and the expression of M-GP progressively increases, whereas the expression of L-GP and B-GP gradually decreases (18).

The prevalence of L-GP and B-GP isoforms in cultured myoblasts may explain why myophosphorylase deficiency was never reproduced in culture. In fact the positivity of regenerating muscle fibers (in vivo and in vitro) to histochemical staining for phosphorylase (19) was interpreted as reexpression of fetal isoforms $(20,21)$, even though other studies had indicated that indeed M-GP was being expressed in immature muscle of myophosphorylase-deficient patients (22).

In this study we investigate the GP isoenzymatic pattern in cultured muscle of five patients with myophosphorylase deficiency that lacked GP activity, M-GP protein, and M-GP mRNA. Cultured muscle was innervated in order to enhance the expression of muscle-specific proteins, and we studied the pattern of GP isoforms in aneural cultures and in cultures innervated for up to $60 \mathrm{~d}$. Transcript analysis in cultures was carried out by primer extension and PCR amplification.

\section{Methods}

Reagents. Purified rabbit muscle phosphorylase $b$, Klenov DNA polymerase I, and restriction enzymes were from Boehringer Mannheim Biochemicals (Mannheim, Germany), RNA ladder and M-MLV reverse transcriptase were from GIBCO BRL (Grand Island, NY), ribonuclease inhibitor (RNasin), exanucleotides, and ampholyne PAGPLATE pH 5.5-8.5 were from Pharmacia-LKB (Uppsala, Sweden), Taq polymerase was from Bioprobe Systems (Montreuil-sous-bois, France), custom synthetized primers for reverse transcription and PCR amplification were obtained from Medprobe (Oslo, Norway), nylon filters (Zetaprobe) were from Bio-Rad Laboratories (Richmond, CA), nitrocellulose filters for Western blot were from Schleicher \& Schuell (Dassel, Germany), $\left[{ }^{32} \mathrm{P}\right] \mathrm{dGTP}(3000 \mathrm{Ci} / \mathrm{mmol})$ was from 
Amersham Int'l. (Amersham, UK). Culture media were from Biochrom-Seromed (Berlin, Germany), FBS was from Hyclone Labs. (Logan, UT), fibroblast and epidermal growth factors were from Collaborative Research (Bedford, MA). All other chemicals were from Sigma Chemical Co. (St. Louis, MO).

Patients. Diagnosis of myophosphorylase deficiency was established in three unrelated patients and in two siblings (total, three males and two females) by clinical criteria, ischemic exercise test, and histochemical and biochemical analyses (Table I).

Cultures. Muscle specimens were obtained by open biopsy from five patients with myophosphorylase deficiency and from two controls undergoing orthopedic surgery. Myoblasts growing from the muscle explants were cultured in monolayer in $35-\mathrm{mm}$ petri dishes (Falcon Labware, Oxnard, CA) as previously described $(23,24)$. Immediately after myoblast fusion, myotubes were cocultured with 12-14-d-old fetal rat spinal cord explants (with dorsal root ganglia attached), as described elsewhere $(16,17)$. In every dish the areas displaying the characteristic appearance of innervated muscle fibers $(16,17)$ were harvested after the spinal cord explants had been carefully excised and discarded. Areas consisting of flat disperse myotubes, generally far away from the spinal cord explants and not showing any spontaneous contraction, were also harvested and considered "noninnervated" muscle fibers. This method of dissection has proven to be highly reliable in our previous studies $(16,18)$. To some dishes spinal cord explants were not added, and these cultures were harvested as "aneural" muscle fibers. Consequently, cultured muscle samples will be referred to as "innervated," "noninnervated," or "aneural."

Few dishes with innervated and noninnervated cultured muscle from control or patient were fixed by air drying, stained for periodic acid-Schiff-positive material ( $0.5 \%$ periodic acid for $3 \mathrm{~min}$, brief wash in water, $10 \mathrm{~min}$ in Schiff's reagent, dehydration in ascending alcohol), and observed by light microscopy.

\section{Biochemical studies}

Biopsied muscle. Samples obtained from muscle biopsy were homogenized in 9 vol of phosphorylase buffer ( $40 \mathrm{mM}$ beta-glycerophosphate, $40 \mathrm{mM} \mathrm{NaF}, 10 \mathrm{mM}$ EDTA, $20 \mathrm{mM}$ beta-mercaptoethanol, pH 6.8). Homogenates were centrifuged at $10,000 \mathrm{~g}$ for $10 \mathrm{~min}$, and supernatants were used. GP activity and glycogen content were measured as described elsewhere (25). Separation of GP isoforms by iso-electric focusing, and gel staining for GP activity was performed as previously described (16) except for the condition of the run, which was: constant power $15 \mathrm{~W}$, limit $1,200 \mathrm{~V}$ and $25 \mathrm{~mA}$, for $3 \mathrm{~h}$ at $5^{\circ} \mathrm{C}$. For protein studies, the samples were run in SDS-PAGE (26) with a linear gradient of $8-13 \%$ acrylamide in the separating gel. Electrophoresis was carried out at constant current ( $25 \mathrm{~mA}$ ) for 4-5 h. The gels were stained with Coomassie brilliant blue or were used for Western blotting.

Table I. Patients' Clinical and Biochemical Data

\begin{tabular}{lccccc}
\hline & Age & Sex & Serum CK & $\begin{array}{c}\text { Muscle } \\
\text { glycogen }\end{array}$ & $\begin{array}{c}\text { Muscle } \\
\text { phosphorylase }\end{array}$ \\
& & & & & $\begin{array}{c}\text { nmol/min } \\
\text { per } m g \\
\text { protein }\end{array}$ \\
& & & U/liter & $g / 100$ & 0 \\
M.M. & 12 & F & 1673 & 3.44 & 0 \\
G.D.* & 30 & F & 1893 & 3.67 & 0 \\
G.R.* & 31 & M & 852 & 1.30 & 0 \\
M.N. & 53 & F & 635 & 2.86 & 0 \\
M.A. & 55 & M & 5000 & ND & 0 \\
Controls (10) & & & $<160$ & $0.41-1.68$ & $9.7-61.3$ \\
& & & & & \\
\hline
\end{tabular}

ND, not determined. * Patients G.D. and G.R. are siblings.
Cultured muscle fibers. Innervated and noninnervated muscle fibers were harvested 20-60 d after the beginning of muscle-spinal cord co-culture. Aneural muscle fibers were harvested 30-40 d after plating. The cells were rinsed in PBS, resuspended in $100 \mu$ l phosphorylase buffer, sonicated ( 3 bursts of $5 \mathrm{~s}$ each at $50 \mathrm{~W}$ ), and centrifuged at $10,000 \mathrm{~g}$ for $5 \mathrm{~min}$. GP activity in the supernatant was measured using the bioluminescent method (27). IEF and SDS-PAGE were performed as described for the samples of muscle biopsy. Protein content was evaluated with the method of Lowry et al. (28).

\section{Immunological studies}

Rabbit muscle phosphorylase $b$ was further purified by gel electrophoresis. The portion of the gel containing a single band of $97 \mathrm{kD}$ was injected into goats with complete Freund's adjuvant, and a booster injection was given $20 \mathrm{~d}$ later. The animals were bled $1 \mathrm{wk}$ after the booster injection. The gamma-globulin fraction was extracted from the total serum and frozen in small aliquots. Normal goat serum was used in control experiments. The antiserum reacted specifically with human M-GP and did not react with L-GP or B-GP. For immunoblots, proteins were electrotransferred from acrylamide gel into nitrocellulose paper. Filters were then incubated for $1 \mathrm{~h}$ in $20 \mathrm{mM}$ Tris-HCl, pH 7.5, $0.5 \mathrm{M} \mathrm{NaCl}, 2 \% \mathrm{BSA}$. The paper was washed four times in $20 \mathrm{mM}$ Tris- $\mathrm{HCl}, \mathrm{pH} 7.5,0.5 \mathrm{M} \mathrm{NaCl}, 0.05 \%$ Tween-20 (TTBS), and incubated for $3 \mathrm{~h}$ with anti-M-GP antiserum diluted 1:50 in TTBS with $1 \%$ BSA. The filters were then washed as described above and incubated 1 $\mathrm{h}$ at $37^{\circ} \mathrm{C}$ with alkaline phosphatase-conjugated donkey anti-goat IgG diluted 1:1000 in TTBS with 1\% BSA. After four washes with saline, the paper was incubated for $10 \mathrm{~min}$ in $4 \mathrm{mg} / \mathrm{ml}$ fast blue $R R$ salt in $0.05 \mathrm{M}$ Tris, $\mathrm{pH}$ 9.2. The reaction was stopped by several washes in distilled water.

\section{Molecular studies}

Northern blot analysis. Total muscle RNA was prepared by the guanidinium hydrochloride/lithium chloride method (29). $100 \mu \mathrm{g}$ yeast tRNA was added as carrier before the first ethanol precipitation to improve RNA yield. 5-10 $\mu$ g of RNA was run on $1.4 \%$ agarose- $2.2 \mathrm{M}$ formaldehyde gel and transferred to a nylon membrane.

${ }^{32} \mathrm{P}$-labeled probe was prepared by random primed labeling of a 460 bp cDNA to the 3' region of human M-GP (a kind gift from Dr. Hwang and Dr. Gunning, University of California, San Francisco) (30). The filters were washed and pretreated for 4-6 $\mathrm{h}$. The hybridization was carried out overnight at $42^{\circ} \mathrm{C}$ in $50 \%$ formamide (vol/vol), $5 \times$ standard sodium phosphate-EDTA, $10 \%$ sodium dextran sulphate, 0.5 $\mathrm{mg} / \mathrm{ml}$ denatured salmon sperm DNA, $1 \times$ Denhardt solution $(0.02 \%$ Ficoll, $0.02 \%$ polyvinylpyrrolidone, $0.02 \% \mathrm{BSA}$ ), with $1-2 \times 10^{6} \mathrm{cpm} /$ $\mathrm{ml}$ of ${ }^{32} \mathrm{P}$-labeled probe. Final washing was in $0.02 \times \mathrm{SSC}, 0.2 \% \mathrm{SDS}$ at $58^{\circ} \mathrm{C}$. The filters were autoradiographed for $4-6 \mathrm{~h}$ at $-70^{\circ} \mathrm{C}$ with an intensifying screen. mRNA length was estimated by comparison with migration standards (0.24-9.5 kb RNA ladder).

Primer extension and PCR amplification. As downstream primer we chose a 20-bp oligo complementary to a stretch of human M-GP cDNA ( 30 ) between nucleotides 514 and 495 ( 5 '-CTGAGACTCAGATGGCCTCA-3': low-M-GP), as upper primer we chose the $22 \mathrm{mer}$ between nucleotides 280 and 301 of the same sequence (5'-CCATGACCGGTTTAAAGTCTTC-3': up-M-GP). Both primers had only limited homology with the corresponding sequences of human L-GP and B-GP and of M-GP from other species (rat, rabbit) $(13,30)$. Total RNA (100-500 ng) and the downstream primer ( $5 \mathrm{pM})$ were annealed by heating $\left(65^{\circ} \mathrm{C}\right)$ for $10 \mathrm{~min}$ and snap-freezing, and then incubated at $37^{\circ} \mathrm{C}$ for $1 \mathrm{~h}$ in the RT-buffer provided by GIBCO BRL, with DTT 0.1 M, dNTP $0.5 \mathrm{mM}, 100 \mathrm{U}$ M-MLV reverse transcriptase, $0.7 \mu \mathrm{l}$ RNasin (final volume $20 \mu \mathrm{l}$ ).

$10 \mu \mathrm{l}$ of the extended products was mixed with $2 \mathrm{pM}$ of low-M-GP, $7 \mathrm{pM}$ of up-M-GP primer, $2.5 \mu \mathrm{l}$ Taq buffer, 1-2 U Taq polymerase, to a final volume of $25 \mu \mathrm{l}$. Amplification was performed on a programmable Thermocycler, (Prem-III System; LEP Scientific Ltd., Milton Keynes, UK) for 30 cycles. One cycle consisted of the following: heat 
denaturation at $94^{\circ} \mathrm{C}$ for $45 \mathrm{~s}$, primer annealing for $45 \mathrm{~s}$ at $47^{\circ} \mathrm{C}$, and primer extension for $90 \mathrm{~s}$ at $72^{\circ} \mathrm{C}$. The $234-\mathrm{bp}$ fragment was resolved by electrophoresis on $8 \%$ nondenaturing polyacrylamide gel and stained with ethidium bromide. Digestion of the PCR product with Haell yielded the expected bands of 133,64 , and $37 \mathrm{bp}$.

\section{Results}

Biopsied muscle. Biopsied muscle of all five patients did not show on immunoblot any reactivity with anti-M-GP antiserum. Control muscle had a strong band comigrating with purified M-GP (Fig. 1). Denaturing gels stained with Coomassie blue showed a distinct band comigrating with purified $\mathrm{M}$ GP in the control but not in the samples from the patients (Fig. 2). Northern blot analysis with human M-GP cDNA showed a band of $3.4 \mathrm{~kb}$ in control muscle, but no signal was detectable in any of the patients, even though the amount of the total RNA loaded on the gel was for the patients twice that of control (Fig. 3).

Primer extension and PCR amplification of RNA from control muscle with M-GP primers yielded the expected product (Fig. 4), but no product was seen after amplification of reverse transcribed RNA from the patients.

Cultured muscle. The pattern of growth and the morphology of patients' cultured muscle did not differ from that of control. There was no vacuolization and no increase of intracellular periodic acid-Schiff-positive material. In accord with previous descriptions (17), 5-10 d after innervation, cultures from patients and controls contained areas of elongated and spontaneously contracting muscle fibers. There was no obvious difference by light microscopy in the pattern of innervation and contraction between patients' and control cultures.

$40 \mathrm{~d}$ after innervation total GP activity in innervated cultured muscle was $64.13 \pm 18.8$ and $54.03 \pm 16.2 \mathrm{nmol} / \mathrm{min}$ per $\mathrm{mg}$ of protein, in cultures from patients and from controls respectively. GP activity was significantly lower in noninnervated cultured muscle: $13.13 \pm 3.6$ (patients) and $14.56 \pm 2.7$ (control) $\mathrm{nmol} / \mathrm{min}$ per $\mathrm{mg}$ of protein (Table II).

When GP isozymes were separated by IEF and stained for GP activity (Fig. 5), a distinct strong band at pH 6.3, as well as other bands at $\mathrm{pH} 6.0-5.6$, were present in the innervated cultured muscle of all five patients as in control. The band at $\mathrm{pH}$ 6.3 was not affected by the omission of $\mathrm{Na}_{2} \mathrm{SO}_{4} 0.7 \mathrm{M}$ from the incubation medium, was the only present in adult human mus-

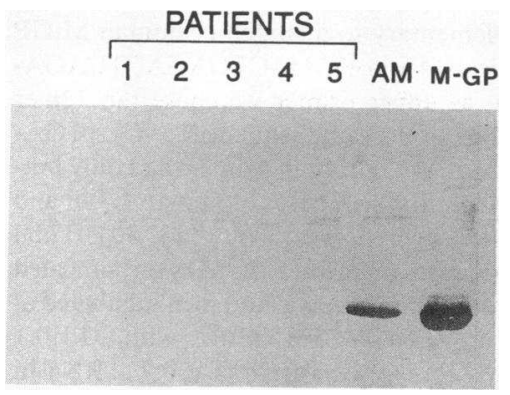

Figure 1. Immunoblot of adult human muscle extracts and of purified rabbit M-GP. Lane $A M$, muscle from a control individual; lanes 1-5, muscle from the patients with myophosphorylase deficiency. Samples containing an equivalent amount of protein were loaded in

lanes $1-5$ and in lane $A M(30-40 \mu \mathrm{g}) ; 2.5 \mu \mathrm{g}$ of purified protein were loaded in lane $M-G P$. The samples were separated by SDS-PAGE and transferred to nitrocellulose paper. The filters were then incubated in 1:50 anti-M-GP antiserum as described in Methods.

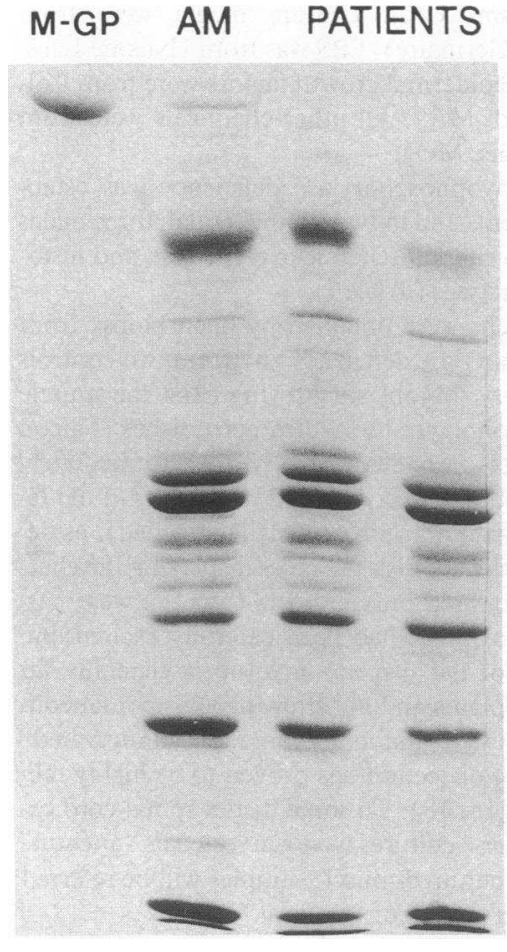

Figure 2. Coomassie brilliant blue staining of SDS-PAGE. Lane $M$ $G P$, purified rabbit muscle phosphorylase; lane $A M$, control human adult muscle; lanes 3 and 4 , adult muscle from two patients. Amount of sample loaded and condition of the run were as described in Fig. 1. Similar results obtained in the other three patients are not shown.

cle (Fig. 5, lane $A M$ ), and corresponds to M-GP. The other bands at lower $\mathrm{pH}$, which are present in cultured muscle but not in adult muscle, correspond to L-GP and B-GP. The bands at pH 6.0-5.8 were also seen in adult liver (Fig. 5, lane $L$, ), and virtually disappeared when $\mathrm{Na}_{2} \mathrm{SO}_{4} 0.7 \mathrm{M}$ was omitted from the incubation medium (not shown).

In patients' and control noninnervated and aneural cultured muscle the amount of GP focusing at $\mathrm{pH} 6.3$ was much lower than in innervated muscle. Nevertheless, a faint but distinct band was present in all aneural and noninnervated samples (an example of aneural muscle culture from one patient is given in Fig. 5, lane 1-,). Densitometric analysis of the gels from cultured muscle innervated for $40 \mathrm{~d}$ showed that the band corresponding to M-GP accounted for $31.92 \pm 10.8 \%$ of total GP in patients' cultures, and $32.45 \pm 11.78 \%$ of total GP in con-

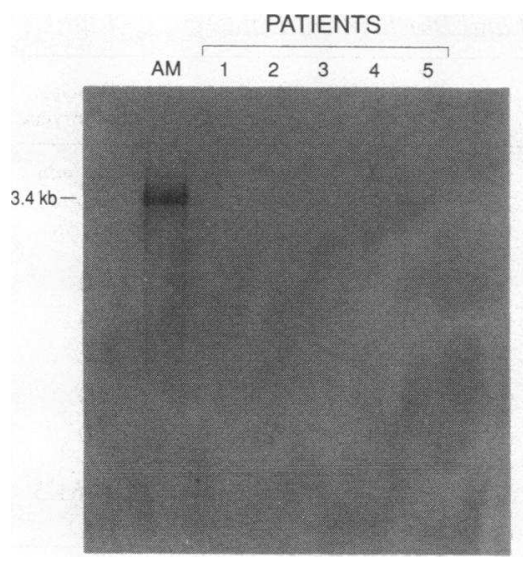

Figure 3. Northern analysis of total adult muscle RNA from control (lane $A M$ ) and from patients with myophosphorylase deficiency (lanes 1-5). $5 \mu \mathrm{g}$ of total RNA were loaded in lane $A M, 10 \mu \mathrm{g}$ of total RNA were loaded in lanes $1-5$. The filters were hybridized with random-primed human M-GP cDNA. The MGP mRNA of expected size $(3.4 \mathrm{~kb})$ is seen only in control muscle; no signal is detectable in the samples of the patients. 


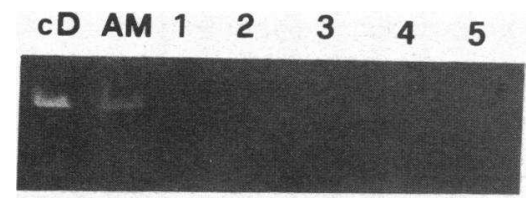

Figure 4. Acrylamide gel of the amplified products of primer-extended RNA from adult muscle of control (lane $A M)$ and patients (lanes $1-5)$. In lane $c D$ the PCR amplification product of M-GP cDNA is shown as reference. The product seen in control muscle is absent in the patients.

trol cultures. M-GP in aneural and noninnervated cultures was in the range of $2-16 \%$ (Table II).

In Western blots of innervated cultured muscle from patients and controls, the anti-M-GP antiserum recognized a band co-migrating with purified M-GP (Fig. $6 a$ ), further confirming the presence of M-GP protein in both patients' and control cultured muscle. A much fainter band was also visible in immunoblots of aneural cultures (Fig. $6 b$ ). The change in M-GP expression in innervated and noninnervated cultured muscle was analyzed in one patient and one control after 20 , 30, 40, and $60 \mathrm{~d}$ of innervation (Fig. 7). There was a steady increase in M-GP (expressed as percent of total GP) in innervated cultured muscle of both patient and control. M-GP after 60-d innervation was $57 \%$ in the patient and 53\% in the control, while in noninnervated muscle M-GP was always below $20 \%$.

Northern blot analysis of total RNA from cultured muscle of patients and control did not show any detectable band.

Primer extension and PCR amplification of total RNA from innervated and aneural muscle yielded in all patients and in controls a single product of the same size as the one obtained after PCR amplification of the human M-GP cDNA or after primer extension and PCR amplification of RNA from adult normal muscle (Fig. 8, $a$ and $b$ ). The identity of the amplified sequence was further confirmed by restriction endonuclesase digestion (HaeII), which gave the expected fragments (not shown).

\section{Discussion}

The cultured muscle of our five patients with myophosphorylase deficiency expressed active M-GP, similar to the isoform found in control adult skeletal muscle by IEF or immunoblot with anti-M-GP antiserum. Both assays had shown complete absence of the enzyme in the adult muscle of all five patients.

Table II. Total GP Activity and M-GP in Patients' and Control Innervated and Noninnervated Cultured Muscle

\begin{tabular}{lcc}
\hline & Total GP & M-GP \\
\hline & $\begin{array}{c}\text { nmol/min per } \\
\text { mg protein }\end{array}$ & \% of total GP \\
Patients' innervated & $64.13 \pm 18.8$ & $32.45 \pm 11.8$ \\
Control innervated & $54.03 \pm 16.2$ & $31.92 \pm 10.8$ \\
Patients' noninnervated & $13.13 \pm 3.6$ & $9.10 \pm 5.3$ \\
Control noninnervated & $14.56 \pm 2.7$ & $8.66 \pm 6.5$
\end{tabular}

Values are expressed as means $\pm \mathrm{SD}$.

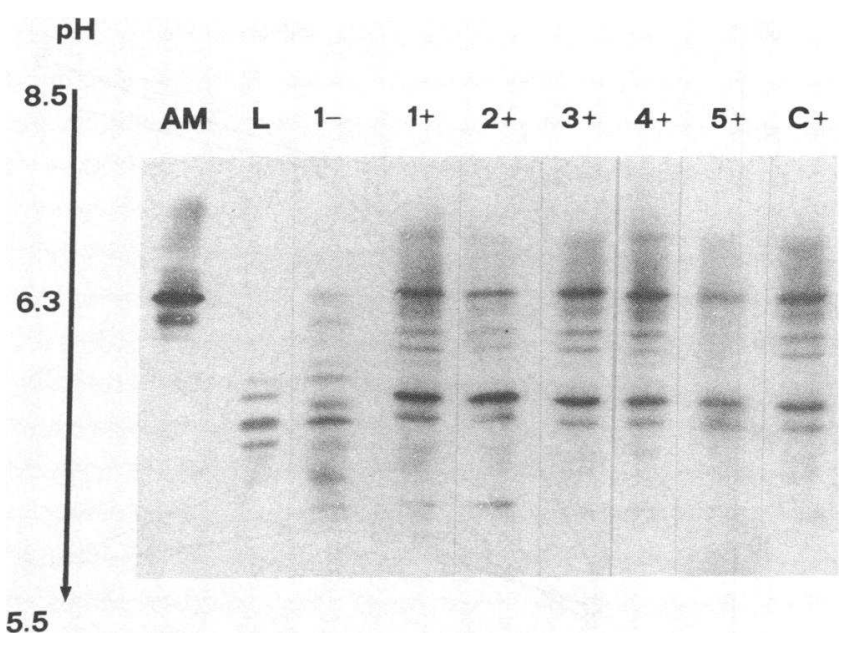

Figure 5. GP isoenzymatic pattern in adult tissues and in innervated and aneural cultured muscle. Lane $A M$, control adult muscle; lane $L$, control adult liver; lane $C+$, control innervated muscle fibers; lanes $1+$ to $5+$, innervated muscle fibers from the five patients with myophosphorylase deficiency; lane $1-$, aneural muscle fibers from one patient. GP isozymes were separated by IEF on PAGE, and GP activity was detected after incubation for $24 \mathrm{~h}$ at $26^{\circ} \mathrm{C}$ in a medium containing $2 \%$ glycogen, $40 \mathrm{mM}$ glucose-1-phosphate, $2 \mathrm{mM} \mathrm{AMP}$, $0.7 \mathrm{M} \mathrm{Na}_{2} \mathrm{SO}_{4}$, and staining in a 1:30 dilution of $4 \%$ iodine, $6 \% \mathrm{KI}$, and $10 \%$ acetic acid.

The amount of M-GP found in cultured muscle was minimal compared with adult muscle, but there was no difference between patients' and control cultures. The degree of M-GP increase after innervation was comparable in patients' and control cultures, suggesting that regulation of M-GP expression in this model is not altered in myotubes from patients with myophosphorylase deficiency.
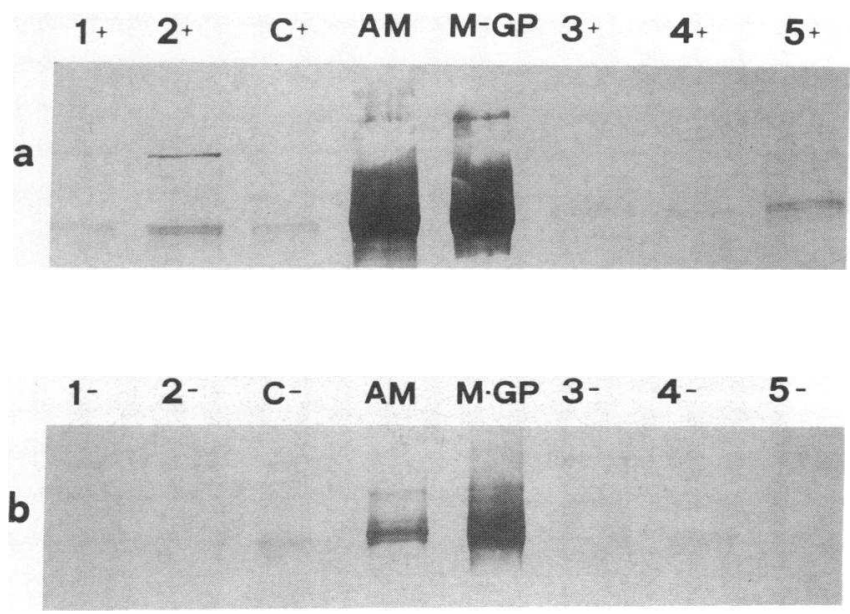

Figure 6. Immunoblots of control and patients' cultured muscle compared with control adult muscle (lanes $A M$ ) and purified M-GP (lanes $M-G P$ ). ( $a$ ) Innervated muscle fibers from control (lane $C+$ ) and patients (lanes $1+$ to $5+$ ). (b) Aneural muscle fibers from control (lane $C-$ ) and patients (lanes $1-$ to $5-$ ). Condition of the run, transfer, and immunoreaction were as described in Fig. 1 and in Methods. 


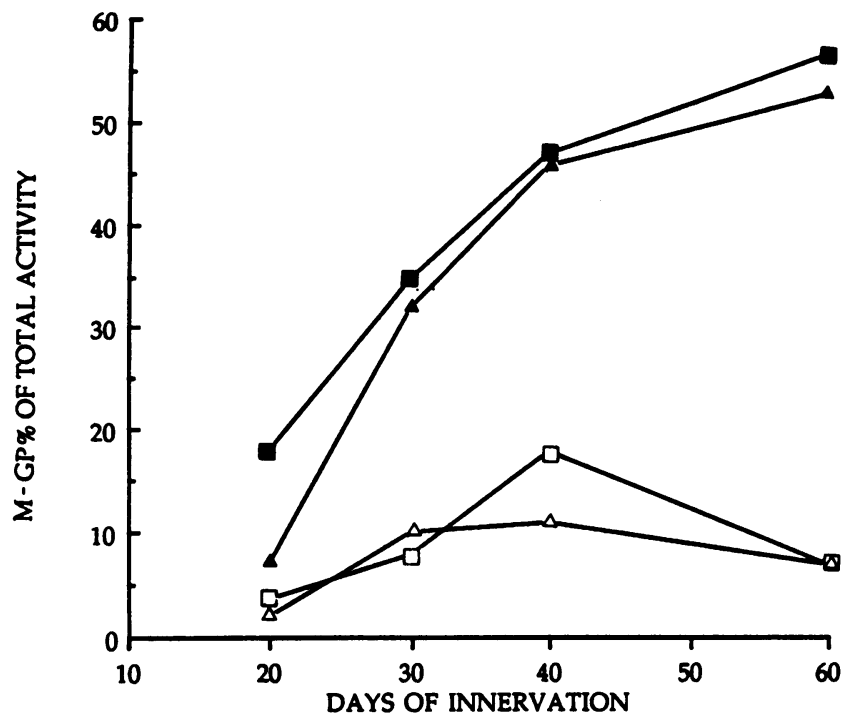

Figure 7. M-GP in innervated and noninnervated muscle fibers of control and of a patient with myophosphorylase deficiency after 20$60 \mathrm{~d}$ of innervation. Open squares, noninnervated muscle from the patient; filled squares, innervated cultured muscle from the patient; open triangles, noninnervated muscle from control; filled triangles, innervated muscle from control.

Our results agree with previous observations reporting the presence of M-GP in cultured muscle from myophosphorylase deficient patients (22), and in addition, provide new information on the response of M-GP expression to innervation and muscle maturation in culture. The presence of very low but detectable M-GP activity and M-GP protein in aneural cultured muscle provides a good control against possible contamination or "enzyme importation" from rat tissue in innervated samples (a small amount of M-GP is normally expressed in rat neural tissue, 31, 32), and indicates that co-culture with spinal cord explants is not required for the synthesis of functional
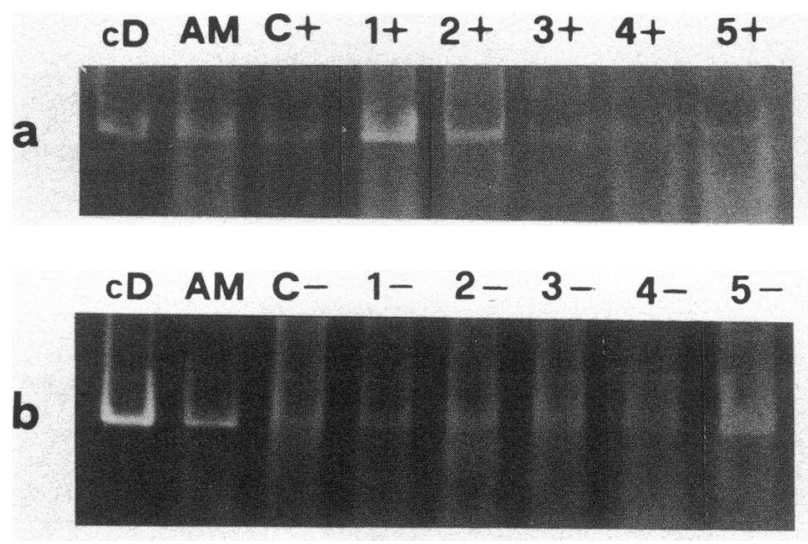

Figure 8. Acrylamide gel of the amplified products of primer-extended RNA from cultured muscle of patients (lanes 1-5) and control (lane $C$ ), and of adult control muscle (lanes $A M$ ). In lane $c D$ the PCR amplification product of human M-GP cDNA is shown as reference. ( $a$ ) Control innervated muscle fibers (lane $C+$ ) and patients' innervated muscle fibers (lanes $1+$ to $5+$ ). (b) Control aneural muscle fibers (lane $C-$ ) and patients' aneural muscle fibers (lanes $1-$ to $5-)$.
M-GP. Contamination from rat cells, or hybridization of rat cells and human myoblasts in this culture system, was ruled out in experiments in which cultured muscle from Duchenne dystrophy patients with deletion of exon 8 in the dystrophin gene was innervated and harvested as described in this study. Exon 8 is present in rat dystrophin gene, and is revealed by the PCR-multiplex method $(33,34)$. PCR amplification of DNA extracted from innervated cultured muscle of Duchenne patients showed the absence of this exon's amplification product (35).

Other authors have failed to detect M-GP in cultured human muscle from patients and control $(20,21)$, probably because their cultures were analyzed at a very immature stage, and the assays utilized were not very sensitive. Slab gel IEF (as used in this study) offers clear advantages in both definition and separation over the assays used in the previous studies (36).

The results of transcriptional analysis are surprising and not easily explained. None of our patients had detectable MGP mRNA in the biopsied muscle. No product was seen after primer extension and PCR amplification, indicating that in these patients M-GP transcript was absent altogether. The small amount of RNA available from cultured muscle was probably not sufficient to appear in Northern blots of either patients' or control samples. By primer extension and PCR amplification of the small amount of RNA available, we were able to show that at least the $3^{\prime}$ end of the M-GP mRNA was present in innervated and in aneural cultured muscle of both patients and control. Therefore the M-GP gene is transcribed in muscle cultures from patients with myophosphorylase deficiency, but we cannot exclude that the mRNA detected is the result of alternate splicing of the M-GP gene. Multiple M-GP mRNA species have been described in animals and human (37). Sequence analysis of the M-GP cDNA and the 3'- and $5^{\prime}$-flanking regions however did not reveal any additional site for transcription initiation $(30,38)$.

The most important aspect of our study is the demonstration that the M-GP gene in five different patients is capable, under certain conditions, of coding for a functional enzyme. This implies that in these patients the reading frame is not defective.

Southern blot analysis of patients with myophosphorylase deficiency failed to show any major deletion of the M-GP gene $(4,39-41)$. A forthcoming report seems to indicate in many patients the presence of a point mutation introducing a stop codon in the first exon of the gene (41a). The characterization of our patients in this respect will be of great interest.

Human M-GP transcription start site has been mapped 76 bp upstream from the translation start site, regulatory elements are present further upstream (38), and maybe also in the $3^{\prime}$ untranslated region (30). In particular a decamer at position -592 has been identified as the tissue-specific regulatory element for human M-GP (38). A transcriptional repressor sequence may be present within the 280 bp between -612 and -892 (38). The factors activating and controlling these cis-acting regulatory elements have not been identified. A mutation in the regulatory sequences, or a defective action of the factors implicated in their control could disrupt the normal repertoire of M-GP expression without affecting the integrity and functionality of the translated protein.

The crucial question is why M-GP is not expressed in patients' adult muscle, but is expressed when the same muscle is 
induced to proliferate in culture. Possible explanations include: activation during early muscle differentiation of a M-GP pseudogene that is shut off in adult muscle, reversion during satellite cells replication of a point mutation blocking M-GP transcription in adult muscle, or existence for M-GP gene of different regulatory mechanisms in myotubes and in adult fibers.

A related sequence mapping on chromosome 10 was described for B-GP (13), but no evidence of M-GP related sequences was ever reported, and recent data on chromosome localization indicate hybridization of M-GP probe to a unique site (40). Reversion of deleterious mutation can occur, but it is a very rare casual event. We observed five different patients and over 200 culture dishes, and the results were always comparable. This makes very unlikely a reversion event, unless one postulates an exceptional frequency and a very strong selective advantage of the reverted cells. The last hypothesis is the most appealing and should be tested. There are several possible mechanisms: developmental-stage specific transcription activation (as observed for GP in Dictyostelium, [42]), message stabilization induced by growth factors or hormones (as seen for muscle-specific creatine kinase and myosin heavy chain mRNAs, [43]), and accumulation during life of factors acting on the repressor sequence.

Sequence analysis of all known regulatory elements of $\mathbf{M}$ GP gene in myophosphorylase deficiency patients, and identification of the DNA-binding proteins acting on them during the various phases of muscle differentiation, will contribute to the understanding of the molecular mechanisms leading to the reexpression of the defective enzyme. One might then seek a way to mimic in vivo the regenerative state to induce M-GP expression in an adult muscle fiber population, as a way to clinically benefit the patients.

\section{Acknowledgments}

We would like to thank Dr. Peter Hwang and Dr. Peter Gunning for the generous gift of the human muscle phosphorylase cDNA.

The financial support of Telethon-Italy (grant to A. Martinuzzi) is gratefully acknowledged.

\section{References}

1. McArdle, B. 1951. Myopathy due to defect in muscle glycogen breakdown. Clin. Sci. (Lond.) 10:13-33.

2. Mommaerts, W. F. H. M., B. Illingworth, C. M. Pearson, R. J. Guillory, and K. Seraydarian. 1959. A functional disorder of muscle associated with the absence of phosphorylase. Proc. Natl. Acad. Sci. USA. 45:791-797.

3. Schmid, R., and R. Mahler. 1959. Chronic progressive myopathy with myoglobinuria: demonstration of a glycogenolytic defect in the muscle. J. Clin. Invest. 38:2044-2058.

4. Gautron, S., D. Daegelen, F. Mennecier, D. Dubocq, A. Kahn, and J. C. Dreyfus. 1987. Molecular mechanisms of McArdle's disease (muscle glycogen phosphorylase deficiency). RNA and DNA analysis. J. Clin. Invest. 79:275-281.

5. Servidei, S., S. Shanske, M. Zeviani, R. Lebo, R. Fletterick, and S. Di Mauro. 1988. McArdle's disease: biochemical and molecular genetic studies. Ann. Neurol. 24:774-781.

6. McConchie, S. M., J. Coakley, R. H. T. Edwards, and R. J. Beynon. 1991 Molecular heterogeneity in McArdle's disease. Biochim. Biophys. Acta. 1096:2632.

7. Dreyfus, J. C., and Y. Alexandre. 1971. Immunological studies on glycogen storage disease type III and V. Demonstration of the presence of an immunoreactive protein in the case of muscle phosphorylase deficiency. Biochem. Biophys. Res. Commun. 44:1364-1370.
8. Feit, H., and M. H. Brooke. 1976. Myophosphorylase deficiency: two different molecular etiologies. Neurology. 26:963-967.

9. Daegelen-Proux, D., A. Kahn, J. Marie, and J. C. Dreyfus. 1981. Research on the molecular mechanisms of McArdle's disease ( muscle glycogen phosphorylase deficiency): use of new protein mapping and immunological techniques. Ann. Hum. Genet. 47:107-115.

10. Proux, D., and J. C. Dreyfus. 1973. Phosphorylase isoenzymes in tissues: prevalence of the liver type in man. Clin. Chim. Acta. 48:167-172.

11. Lebo, R. V., F. Gorin, R. J. Fletterick, F. T. Kao, M. C. Cheung, B. D. Bruce, and Y. W. Kan. 1984. High resolution chromosome sorting and DNA spot analysis assign McArdle's syndrome to chromosome 11. Science (Wash. DC). 225:57-59.

12. Newgard, C. B., R. J. Fletterick, L. A. Anderson, and R. V. Lebo. 1987. The polymorphic locus for glycogen storage disease VI (liver glycogen phosphorylase) maps to chromosome 14. Am. J. Hum. Genet. 40:351-364.

13. Newgard, C. B., D. R. Littman, C. van Genderen, M. Smith, and R. J. Fletterick. 1988. Human brain glycogen phosphorylase: cloning, sequence analysis, chromosomal mapping, tissue expression and comparison with the human liver and muscle isozymes. $J$. Biol. Chem. 263:3850-3857.

14. Richter, F., H. J. Böhme, and E. Hofmann. 1983. Developmental changes of glycogen phosphorylase $\mathrm{b}$ isozymes in rat tissues. Biomed. Biochim. Acta. 42:1229-1235.

15. Gorin, F. A., R. L. Mullinax, P. C. Ignacio, R. L. Neve, and D. M. Kurnit. 1987. McArdle's \& Hers' diseases: glycogen phosphorylase transcriptional expression in human tissues. J. Neurogenet. 4:293-308.

16. Martinuzzi, A., V. Askanas, T. Kobayashi, W. K. Engel, and S. Di Mauro. 1986. Expression of muscle-gene-specific isozymes of phosphorylase and creatine kinase in innervated cultured human muscle. J. Cell. Biol. 103:1423-1429.

17. Askanas, V., H. Kwan, R. Alvarez, W. K. Engel, T. Kobayashi, A. Martinuzzi, and E. Hawkins. 1987. De-novo neuromuscular junction formation in human muscle fibers cultured in monolayer and innervated by fetal rat spinal cord: ultrastructural and ultrastructural-cytochemical studies. J. Neurocytol. 16:523537.

18. Martinuzzi, A., V. Askanas, T. Kobayashi, and W. K. Engel. 1988. Asynchronous regulation of muscle specific isozymes of creatine kinase, glycogen phosphorylase, lactic dehydrogenase and phosphoglycerate mutase in innervated and non-innervated cultured human muscle. Neurosci. Lett. 89:216-222.

19. Roelofs, R. I., W. K. Engel, and P. B. Chauvin. 1972. Histochemical phosphorylase activity in regenerating muscle fibers from myophosphorylase-deficient patients. Science (Wash. DC). 177:795-797.

20. Sato, K., F. Imai, I. Hatayama, and R. I. Roelofs. 1977. Characterization of glycogen phosphorylase isoenzymes present in cultured skeletal muscle from patients with McArdle's disease. Biochem. Biophys. Res. Commun. 78:663-668.

21. Di Mauro, S., S. Arnold, A. Miranda, and L. P. Rowland. 1978. McArdle disease: the mystery of reappearing phosphorylase activity in muscle culture. A fetal isoenzyme. Ann. Neurol. 3:60-66.

22. Meienhofer, M. C., V. Askanas, D. Proux-Daegelen, J. C. Dreyfus, and W. K. Engel. 1977. Muscle-type phosphorylase activity present in muscle cells cultured from three patients with myophosphorylase deficiency. Arch. Neurol. 34:779-781.

23. Askanas, V., and W. K. Engel. 1975. New program for investigating adult human skeletal muscle grown aneurally in tissue culture. Neurology. 25:58-67.

24. Askanas, V., and G. Hawkins. 1985. Synergistic influence of polypeptide growth factors on cultured human muscle. Arch. Neurol. 42:749-752.

25. Di Mauro, S., G. B. Hartwig, A. P. Hays, A. B. Eastwood, R. Franco, M Olarte, M. Chang, A. D. Roses, M. Fetell, R. S. Schoenfeldt, and L. Z. Stern. 1979. Debrancher deficiency: neuromuscular disorder in five adults. Ann. Neurol. $5: 422-436$.

26. Laemmli, U. K. 1970. Cleavage of structural proteins during the assembly of the head of the bacteriophage T4. Nature (Lond.). 227:680-685.

27. Hughes, R. A. 1983. Bioluminescent assay for glycogen phosphorylase in cultured cells. Anal. Biochem. 131:318-323.

28. Lowry, O. H., N. J. Rosenbrough, A. L. Farr, and R. J. Randall. 1951 Protein measurement with folin phenol reagent. J. Biol. Chem. 193:265-275.

29. Cathala, G., J. F. Savouret, B. Mendez, B. L. West, M. Karin, J. A. Martial, and J. D. Baxter. 1983. A method for isolation of intact, translationally active ribonucleic acid. DNA (New York). 2:329-335.

30. Hwang, P. K., Y. P. See, A. M. Vincentini, M. A. Powers, R. J. Fletterick, and M. M. Crerar. 1985. Comparative sequence analysis of rat, rabbit, and human muscle glycogen phosphorylase cDNAs. Eur. J. Biochem. 152:267-274.

31. David, E. S., and M. M. Crerar. 1986. Quantitation of muscle glycogen phosphorylase mRNA and enzyme amounts in adult rat tissues. Biochim. Biophys. Acta. 880:78-90.

32. Crerar, M. M., J. W. Hudson, K. E. Matthews, E. S. David, and G. B. Golding. 1988. Studies on the expression and evolution of the glycogen phosphorylase gene family in the rat. Genome. 30:582-590.

33. Meng, G., W. Kress, S. Scherpf, T. Bettecken, W. Feichtinger, W. Schempp, M. Schmid, and C. R. Muller. 1991. A comparison of the dystrophin gene structure in primates and lower vertebrate. In Muscular Dystrophy Re- 
search: From Molecular Diagnosis toward Therapy. C. Angelini, G. A. Danieli, and D. Fontanari, editors. Excerpta Medica Elsevier Science Publishers, Amsterdam. 23-30.

34. Chamberlain, J. S., R. A. Gibbs, J. E. Ranier, and C. T. Caskey. 1988. Deletion screening of the Duchenne muscular dystrophy locus via multiplex DNA amplification. Nucleic Acids Res. 16:11141-11156.

35. Fanin, M., E. P. Hoffman, F. A. Saad, A. Martinuzzi, G. A. Danieli, and C. Angelini. 1993. Dystrophin positive myotubes in innervated muscle cultures from Duchenne and Becker muscular dystrophy patients. Neuromuscular Disorders. 3:113-127.

36. Sato, T., and K. Sato. 1980. Microheterogeneity of the rat glycogen phosphorylase liver-type isozyme. Biochim. Biophys. Acta. 612:344-351.

37. Gorin, F., P. Ignacio, R. Gelinas, and R. Carlsen. 1989. Abnormal expression of glycogen phosphorylase genes in regenerated muscle. Am. J. Physiol. 257:C495-C503.

38. Lockyer, J. M., and J. B. McCracken, Jr. 1991. Identification of tissue-specific regulatory element within the human muscle glycogen phosphorylase gene. J. Biol. Chem. 266:20262-20269.

39. Anderson, L., R. J. Fletterick, S. Di Mauro, P. Hwang, F. Gorin, and R.
Lebo. 1986. Restriction enzyme analysis of McArdle's syndrome gene locus. Muscle \& Nerve. 9:231. (Abstr.)

40. Lebo, R. V., L. A. Anderson, S. DiMauro, E. Lynch, P. Hwang, R. Fletterick. 1990. Rare McArdle disease locus polymorphic site on 11 q13 contains CpG sequence. Hum. Genet. 86:17-24.

41. Burke, J., P. Hwang, L. Anderson, R. Lebo, F. Gorin, R. Fletterick. 1987. Intron/exon structure of the human gene for the muscle isozyme of glycogen phosphorylase. Proteins. 2:177-187.

4la. Tsujino, S., S. Shanske, and S. DiMauro. 1993. Molecular basis of myophosphorylase deficiency (McArdle's disease). Neurology. 40(Suppl. 2):279a. (Abstr.)

42. Rutherford, C. L., R. B. Peery, J. F. Sucic, Y. Yin, P. V. Rogers, S. Luo, and O. Selmin. 1992. Cloning, structural analysis, and expression of the glycogen phosphorylase-2-gene in Dyctostelium. J. Biol. Chem. 267:2294-2302.

43. Pontecorvi, A., J. R. Tata, M. Phyillaier, and J. Robbins. 1988. Selective degradation of mRNA: the role of short-lived proteins in differential destabilization of insulin-induced creatine phosphokinase and myosin heavy chain mRNAs during rat skeletal muscle L6 cell differentiation. EMBO (Eur. Mol. Biol. Organ.) J. 7:1489-1495. 